\title{
PENGARUH ONLINE BOOKING \& OFFLINE BOOKING TERHADAP PENINGKATAN OCCUPANCY PADA MARC HOTEL PASSER BAROE
}

\author{
Agata Claudia Mawarni \\ Program Studi Magister Manajemen Universitas Tarumanagara \\ agataclaudia@yahoo.com \\ Eko Harry Susanto \\ Program Studi Magister Manajemen Universitas Tarumanagara
}

Masuk : 07-12-2019, revisi : 07-01-2020 diterima untuk diterbitkan : 07-01-2020

\begin{abstract}
Lifestyle is a piece of human life nowadays. People do many things to express their desire, and also to try new experience. One of such things is traveling. The technology growth has enabled simplicity and ease of access to all necessity, such as transportation, equipment, and more importantly, lodgings such as hotels and inns.

Based on the improvement of facility, people now can easily book hotels using only a few gestures. Online travel agency industry is growing, and partnership between hotels and the agency is getting thicker. Booking via apps or site only takes a few seconds to do, yet some people still prefer booking directly through phone or reception desk staff. Based on that thought, a goal is set to look deeper on both online and offline booking effects on hotel's occupancy rate.

The data used for making this research is from Marc Hotel Passer Baroe. The data was taken from the company monthly statistics report from January to October 2019. The conclusion was that the online booking partially affects the occupancy rate negatively, and offline booking partially affects the positively. Both variables simultaneously affect the positively. Thus, the company should focus on better promotion on offline booking programs, encouraging patron to book directly to them instead of $3^{\text {rd }}$ party.
\end{abstract}

Keywords : Online Booking, Offline Booking, Occupancy Rate, Lifestyle

Abstrak: Gaya hidup adalah bagian dari hidup manusia masa kini. Orang-orang melakukan banyak hal untuk mengekspresikan keinginan mereka, dan juga untuk mencoba pengalaman baru. Salah satu dari hal-hal tersebut adalah traveling. Kemajuan teknologi memungkinkan kepraktisan dan kemudahan akses untuk berbagai keperluan, seperti transportasi, peralatan, dan lebih penting lagi, tempat bermalam seperti hotel dan penginapan.

Berdasarkan kemajuan fasilitas tersebut, banyak orang dapat memesan kamar hotel secara mudah hanya dengan sedikit bergerak. Industri online travel agency sedang bertumbuh, dan kerjasama antara hotel dan agensi tersebut semakin banyak terlihat. Pemesanan lewat aplikasi atau situs hanya memerlukan waktu sekejap saja, walau tetap ada orang-orang yang masih lebih memilih memesan kamar melalui telepon atau langsung di meja resepsi. Atas pemikiran tersebut, maka dilakukanlah sebuah penelitian untuk melihat efek online dan offline booking terhadap occupancy rate sebuah hotel.

Data yang digunakan untuk melakukan penelitian ini didapat dari Marc Hotel Passer Baroe. Data tersebut diambil dari laporan statistik bulanan bulan Januari sampai Oktober 2019. Kesimpulan yang didapat yaitu online booking memiliki pengaruh parsial terhadap occupancy rate secara negatif, dan offline booking memiliki pengaruh parsial terhadap occupancy rate secara positif. Kedua variabel mempengaruhi occupancy rate secara positif apabila digunakan bersama-sama. Oleh karena itu, perusahaan sebaiknya lebih fokus membangun promosi terhadap program offline booking, menarik konsumen untuk memesan secara langsung disbanding menggunakan jasa pihak ketiga. 
Kata Kunci : Online Booking, Offline Booking, Occupancy Rate, Gaya Hidup

\section{PENDAHULUAN}

Pada masa kini, gaya hidup merupakan hal yang penting bagi manusia dan berpengaruh besar pada kehidupan sosial, tidak terkecuali pada masyarakat Indonesia. Dalam era global, akses terhadap berbagai macam hal sudah sangat canggih dan praktis, sehingga memudahkan masyarakat dalam melakukan berbagai hal. Kemudahan dalam menunjang kebutuhan gaya hidup memperluas pilihan kegiatan yang dapat dilakukan.

Salah satu kegiatan penunjang gaya hidup yang dimudahkan pada era ini adalah traveling. Kemudahan-kemudahan yang dimaksud adalah adanya kemudahan dalam memesan tiket layanan transportasi umum, baik tiket pesawat, bus, maupun kereta. Selain layanan tranportasi, hal lain yang dimudahkan adalah pemesanan hotel. Pemesanan hotel dapat dilakukan dengan menggunakan aplikasi pada smartphone ataupun via telepon terhadap hotel yg dituju.

Hotel merupakan bisnis jasa akomodasi yang didalamnya terdapat unsur pelayanan, kenyamanan, serta fasilitas penginapan yang dibutuhkan bagi mereka yang menghendaki sarana penginapan untuk kepentingan keluarga maupun liburan. Selain itu, hotel juga dapat digunakan sebagai keperluan bisnis. Industri hotel mulai marak di Indonesia, banyak digunakan untuk keperluan rapat-rapat, terutama oleh pihak pemerintahan, perusahaan swasta, dan komunitas. Hotel juga berfungsi sebagai sarana perayaan pernikahan karena hotel memiliki ballroom atau ruang serbaguna.

Menurut Zebua (2018) aktivitas Online Travel Agencies (OTA), sebagai cabang commerce, tak dapat dipandang sebelah mata. Belum lagi pergeseran gaya hidup Indonesia saat ini ketika masyarakat kelas menengah ke atas pengeluaran konsumsinya lebih fokus untuk pengalaman (experiences) daripada untuk barang-barang konsumsi fisik (materi).

Pemesanan kamar hotel mulai dianggap penting pada era ini, karena mulai mempengaruhi gaya hidup seseorang, dan juga berkaitan dengan urusan pekerjaan atau bisnis, baik perseorangan maupun perusahaan atau pemerintahan, maka dari itu dilakukanlah penelitian mengenai online booking dan offline booking terhadap peningkatan occupancy rate untuk melihat sejauh mana kedua variabel tersebut mempengaruhi tingkat okupansi.

\section{METODOLOGI PENELITIAN}

Penelitian yang dilakukan adalah penelitian deskriptif korelasional. Penelitian deskriptif digunakan untuk memberikan penjelasan karakteristik mengenai objek penelitian, dengan tujuan untuk mendapatkan pengertian mengenai karakteristik, profil, serta dapat pula menjelaskan aspek yang relevan dari fenomena tehadap objek penelitian, sehingga dapat ditarik suatu gambaran bahwa penelitian deskriptif digunakan untuk memberi deskripsi atau gambaran terhadap objek yang diteliti. Dalam penelitian ini, pendekatan deskriptif digunakan untuk memberi gambaran mengenai tingkat okupansi Marc Hotel Passer Baroe dalam jangka waktu sepuluh bulan.

Sedangkan pendekatan korelasional digunakan untuk menunjukkan adanya hubungan antara dua variabel. Tujuan pendekatan korelasional adalah untuk menentukan ada atau tidaknya suatu hubungan antara beberapa variabel tersebut. Demikian juga dalam penelitian ini, dimana pendekatan korelasional digunakan untuk mengetahui seberapa besar pengaruh pemesanan kamar yang dilakukan secara online maupun offline untuk meningkatkan tingkat okupansi.

Metode analisis yang digunakan yaitu analisis regresi linear berganda, dengan metode analisis tersebut akan terlihat hubungan antara variabel independent terhadap variable dependen. Rumus yang digunakan adalah rumus menurut Akdon dan Riduwan (2007), yaitu:

$$
\mathrm{Y}=\mathrm{b} 0+\mathrm{b} 1 \mathrm{X} 1+\mathrm{b} 2 \mathrm{X} 2+\mathrm{e}
$$




\section{Dimana :}

$\mathrm{Y} \quad=$ Volume penjualan (unit terjual)

$\mathrm{X} 1 \quad=$ Harga jual (Rupiah)

$\mathrm{X} 2=$ Biaya promosi (Rupiah)

b0 = Nilai konstanta

$\mathrm{b} 1, \mathrm{~b} 2=$ Koefisien regresi

\section{HASIL DAN PEMBAHASAN}

Tabel 1

Deskripsi Nilai Occupancy, OTA dan Offline Booking

Descriptive Statistics

\begin{tabular}{lr|r|r} 
& \multicolumn{1}{c}{ Mean } & Std. Deviation & \multicolumn{1}{l}{ N } \\
\hline Occupancy & 43.2562 & 23.61292 & 281 \\
\hline OTA & 40.65 & 22.125 & 281 \\
\hline Offline_booking & 123.79 & 85.186 & 281 \\
\hline
\end{tabular}

Berdasarkan Tabel 1 di atas, dapat ditarik deskripsi umum sebagai berikut:

1. Data OTA memiliki rata-rata sebanyak 40,65 kali, dengan deviasi standar sebesar 22,125.

2. Data offline booking memiliki rata-rata sebanyak 123,79 kali, dengan deviasi standar sebesar 85,186.

3. Data occupancy rate memiliki rata-rata sebesar 43,2562\%, dengan deviasi standar sebesar 23,61292. berikut:

Berdasarkan hasil pengujian di atas maka didapatkan persamaan regresinya yaitu sebagai

Keterangan:

$$
\begin{gathered}
Y^{\prime}=a+b_{1} X_{1}+b_{2} X_{2} \\
Y^{\prime}=0,025+(-0,158) X_{1}+0,053 X_{2}
\end{gathered}
$$

$$
\begin{array}{ll}
\mathrm{Y}^{\prime} & =\text { Occupancy Rate } \\
\mathrm{A} & =\text { Konstanta } \\
\mathrm{b}_{1}, \mathrm{~b}_{2} & =\text { Koefisien Regresi } \\
\mathrm{X}_{1} & =\text { Online Booking } \\
\mathrm{X}_{2} & =\text { Offline Booking }
\end{array}
$$

Berdasarkan tabel tersebut hasil yang telah diperoleh dari koefisien regresi, maka dapat dilihat bahwa nilai konstantanya yaitu 0,025 artinya jika online booking (OTA) $\left(\mathrm{X}_{1}\right)$ dan offline booking $\left(\mathrm{X}_{2}\right)$ nilainya 0 maka occupancy rate nilainya 0,025 . Dan juga terjadi korelasi negatif antara variabel OTA dengan variabel occupancy rate.

Tabel 2

Hasil Uji T

\section{Coefficients $^{\mathrm{a}}$}

\begin{tabular}{llr|r} 
Model & & \multicolumn{1}{c|}{$\mathrm{t}$} & \multicolumn{1}{c}{ Sig. } \\
\hline \multirow{2}{*}{1} & (Constant) & .022 & .983 \\
\cline { 2 - 4 } & DIFF(OTA,1) & -2.811 & .005 \\
\cline { 2 - 4 } & DIFF(Offline_booking,1) & 3.327 & .001 \\
\hline
\end{tabular}

a. Dependent Variable: DIFF(Occupancy,1) 
Pada tabel di atas, hasil uji t variabel online booking $\left(\mathrm{X}_{1}\right)$ terhadap occupancy rate $(\mathrm{Y})$ menunjukan tingkat signifikansi $0<0,05$. Karena tingkat signifikansi $<0,05$, dan juga berdasarkan tabel didapat $\mathrm{t}$ hitung sebesar -2,811 dan didapatkan $\mathrm{t}$ tabel sebesar 2,253652637 (ms.excel(=tinv0.025,277)), $-2,811<-2,320711$ artinya $-\mathrm{t}_{\text {hitung }}<-\mathrm{t}$ tabel, maka $\mathrm{H}_{\mathrm{a}}$ diterima dan dapat disimpulkan bahwa terdapat pengaruh yang signifikan secara negatif antara variabel online booking terhadap occupancy rate yang berarti $\mathrm{H}_{0}$ ditolak dan $\mathrm{H}_{\mathrm{a}}$ diterima, artinya secara parsial terdapat pengaruh yang signifikan secara negatif antara variabel online booking terhadap variabel occupancy rate. Jadi hasil analisis di atas menunjukan bahwa variabel online booking berpengaruh secara negatif terhadap occupancy rate Marc Hotel Passer Baroe.

\section{KESIMPULAN DAN SARAN}

Penelitian ini dilakukan untuk mengetahui pengaruh online booking dan offline booking terhadap occupancy rate Marc Hotel Passer Baroe pada bulan Januari - Oktober 2019. Berdasarkan data yang telah diteliti maka dapat disimpulkan sebagai berikut:

1. Online booking memiliki pengaruh yang signifikan secara negatif terhadap occupancy rate Marc Hotel Passer Baroe.

2. Offline booking memiliki pengaruh yang signifikan secara positif terhadap occupancy rate Marc Hotel Passer Baroe.

3. Hasil pengujian mengatakan bahwa variabel online booking $\left(\mathrm{X}_{1}\right)$ dan variabel offline booking $\left(\mathrm{X}_{2}\right)$ secara simultan memiliki pengaruh yang kuat secara positif terhadap occupancy rate Marc Hotel Passer Baroe.

Disamping kesimpulan, terdapat pula saran bagi penelitian ini. Berdasasarkan kesimpulan-kesimpulan di atas maka penulis menyarankan beberapa hal sebagai berikut:

1. Kepada Marc Hotel Passer Baroe

Melihat hasil kesimpulan bahwa online booking memiliki pengaruh secara negatif, dimana hal tersebut berarti bahwa setiap terjadi kenaikan online booking maka akan terjadi penurunan occupancy rate, maka sebaiknya perusahaan lebih memfokuskan diri pada efisiensi offline booking. Offline booking memiliki pengaruh signifikan secara positif, dimana hal tersebut berarti bahwa setiap terjadi kenaikan offline booking maka akan terjadi kenaikan occupancy rate. Dari kedua hal tersebut maka akan lebih baik agar perusahaan melakukan peningkatan dalam strategi promosi sehingga semakin meningkatkan offline booking, sehingga akan meningkatkan occupancy rate.

2. Kepada Peneliti

Melihat dari hasil penelitian yang memiliki banyak keterbatasan ini, peneliti selanjutnya diharapkan dapat menggunakan faktor-faktor lainnya seperti produk, fasilitas hotel, dan lokasi hitel yang kemungkinan mempengaruhi occupancy rate selain online booking dan offline booking dengan referensi yang lebih banyak. Referensi tersebut dapat didapat dengan mencari penelitian terdahulu yang membahas topik yang sama, terutama lebih akurat lagi apabila penelitian tersebut juga membahas detail seperti fakta bahwa hotel yang diteliti adalah hotel yang bintang 4 yang menggunakan online travel agent juga. Selain itu juga diharapkan agar peneliti dapat menggunakan teori yang lebih lengkap lagi untuk menunjang penelitian dengan lebih baik.

\section{DAFTAR PUSTAKA}

Abdullah, A.A \& Hamdan, M.H. (2012). International Journal of Business and Social Science: Internal Success Factor of Hotel Occupancy Rate Vol. 3 No.22. diunduh dari: https://ijbssnet.com/journals/Vol_3_No_22_Special_Issue_November_2012/18.pdf

Akdon, Riduwan. (2007). Rumus dan Data dalam Aplikasi Statistika. Bandung: Alfabeta

Anindhita, W., Arisanty, M., \& Rahmawati, D. (2016). Analisis Penerapan Teknologi Komunikasi Tepat Guna Pada Bisnis Transportasi Ojek Online. Jakarta: Universitas Bakrie Indocompac 
Arisanty, D \& Farida, L.E. (2018). Perkembangan Layanan Transportasi Masyarakat Di Era Digital (Studi Tentang Ojek Online "Go-Jek" di Banjarmasin. Banjarmasin: Politeknik Negeri Banjarmasin

Australian Tourism Data Wirehouse. 2013.Tutorial 39a On Line Travel Agents 101.Australia: Australian Tourism Data Warehouse.

Bagyono. (2006). Teori dan Praktek Hotel Front Office. Bandung: Alfabeta

Darsono. (1992). Kantor Depan Hotel (Front Office). Jakarta: PT Grasindo

Diah pradiatiningtyas (2015). Analisa Buying Behavior pada Online Travel Agent AMIK BSI Bandung

Ghozali, Imam. (2011). "Aplikasi Analisis Multivariate Dengan Program SPSS”. Semarang: Badan Penerbit Universitas Diponegoro.

Ghozali, Imam. (2016). Aplikasi Analisis Multivariate Dengan Program IBM SPSS 23, Cetakan kedelapan. Semarang: Universitas Diponegoro.

Hendriyanti, L. (2019). Jurnal: Pengaruh Online Travel Agent Terhadap Pemesanan Kamar di Hotel Mutiara Malioboro Yogyakarta. diunduh dari: file:///Users/agataclaudia/Downloads/01_PENGARUH\%20ONLINE\%20TRAVEL\%20 AGENT\%20TERHADAP\%20PEMESANAN\%20KAMAR\%20DI\%20HOTEL\%20M UTIARA\%20MALIOBORO\%20YOGYAKARTA.pdf

Kustini, H. (2017). General Hotel Management. Yogyakarta: Penerbit Deepublish

Manurung, H \& Tarmoezi, T. (2007). Manajemen Front Office Hotel. Bekasi Timur: Kesaint Blanc - IKAPI

Noor, Juliansyah. (2015). Metodologi Penelitian : Skripsi, Tesis, Disertasi dan Karya Ilmiah. Jakarta: Kencana.

Nugroho, Agung. (2005). Strategi Jitu Memilih Metode Statistic Penelitian Dengan SPSS, Yogyakarta: Andi Yogyakarta.

Pratisto, Arif. (2009). Statistik Menjadi Mudah dengan SPSS 17. Jakarta: Elex Media Komputindo.

Saraswati, D. K. (2019). Berita Resmi Statistik Provinsi DKI Jakarta No. 08/02/31/Th.XXI, 01 Februari 2019

Sugiyono. (2013). Metode Penelitian Pendidikan Pendekatan Kuantitatif, Kualitatif, dan R\&D. Bandung: Alfabeta.

Sugiyono. (2015). Metode Penelitian Pendidikan (Pendekatan Kuantitatif, Kualitatis, dan R\&D). Bandung: Alfabeta.

Susanto, E. H. (2010). Komunikasi Manusia: Esensi dan Aplikasi dalam Dinamika Sosial Ekonomi Politik. Jakarta: Mitra Wacana Media

Susanto, E. H. (2018). Komunikasi Manusia: Teori dan Praktik Dalam Penyampaian Gagasan. Jakarta: Mitra Wacana Media

William, C. A. (1999). Risk Management and Insurance. New York: Mc.Graw Hill.

Winardi. (1999). Pengantar Manajemen Penjualan. Bandung: PT. Citra Aditya Bakti.

Zebua, F.(2018). Laporan Daily Social: Survei Online Travel Agencies (OTA) 2018. Diunduh dari: https://dailysocial.id/post/laporan-dailysocial-survey-online-travel-agencies-ota2018 